Raymond, W. F., Harris, C. E. \& Harker, V. G. (1953b). F. Brit. Grassl. Soc. 8, 3 I 5.

Shumard, R. F., Bolin, D. W. \& Eveleth, D. F. (1957). Amer. F. vet. Res. r8, 330.

Spedding, C. R. W. (I953). F. Helminth. 27, 9.

Spedding, C. R. W. (1954). F. comp. Path. 64, 5.

Spedding, C. R. W. (1955). F. Brit. Grassl. Soc. ro, 35.

Spedding, C. R. W. \& Brown, T. H. (1957a). Ұ. agric. Sci. 48, 286.

Spedding, C. R. W. \& Brown, T. H. (1957b). F. agric. Sci. 49, 223.

Spedding, C. R. W. \& Brown, T. H. (1957c). F. agric. Sci. 49, 229

Spedding, C. R. W., Brown T. H. \& Large, R. V. (1960). Proc. int. Grassl. Congr. vilı. Reading, p. 718.

Spedding, C. R. W., Large, R. V. \& Brown, T. H. (1961). Vet. Rec. 73, 1428.

Stewart, J. (1932-3). Rep. Inst. Anim. Path. Univ. Camb. p. $5^{8 .}$

Taylor, E. L. (1942). Vet. Rec. 54, 377.

Taylor, E. L. (1953). F. R. agric. Soc. 14, 153.

Wallace, L. R. (1948). F. agric. Sci. 38, 93, 243, 367 .

\title{
The effect of nutrition on the growth of Fasciola hepatica in its snail host
}

By S. B. Kendall and C. B. Ollerenshaw, Ministry of Agriculture, Fisheries and Food, Central Veterinary Laboratory, New Haw, Weybridge, Surrey

Ever since the time of Thomas (1883) it has been accepted that the snail Limnaea truncatula plays an essential role in the epidemiology of fascioliasis. Thomas, whose investigations had been prompted by catastrophic losses of sheep in Britain during the years $1879-80$, commented on the enormous numbers of snails that could at times be found, and it has been commonly assumed that there is a direct relationship between the numbers of the vector and the intensity of infection reaching the definitive host. Factors other than the size of the snail population are, however, involved.

\section{Field studies}

At Weybridge, during the course of work designed to improve methods of control of fascioliasis in Britain, population studies on a number of habitats of L. truncatula have been combined with observations on the rate of infection with Fasciola hepatica. The results of two such studies, one on a 'flush' habitat (see Ollerenshaw, I958) on a hill farm in Scotland and the other on a shallow ditch habitat on a lowland farm in Wales are here reported.

On the hill farm in Scotland moisture conditions favourable to the snail were maintained over the restricted area of the habitat throughout the period of observation and on the few occasions when the population was sampled large numbers of small snails were found. In Fig. I the histograms show the size structure of the population. The forms of the histograms for May and December 1953 were repeated in the following year (Fig. I). Infected snails were found in each of the four collections. On this occasion the percentage of infected snails was small so that there may be some doubt about the validity of the observation; nevertheless it does appear that there are greater variations in the sizes of the parasite populations than in those of the snail populations. Certainly there is no evidence of a direct relationship between the numbers of snails and the numbers of parasites. 
Flush habitat Scotland
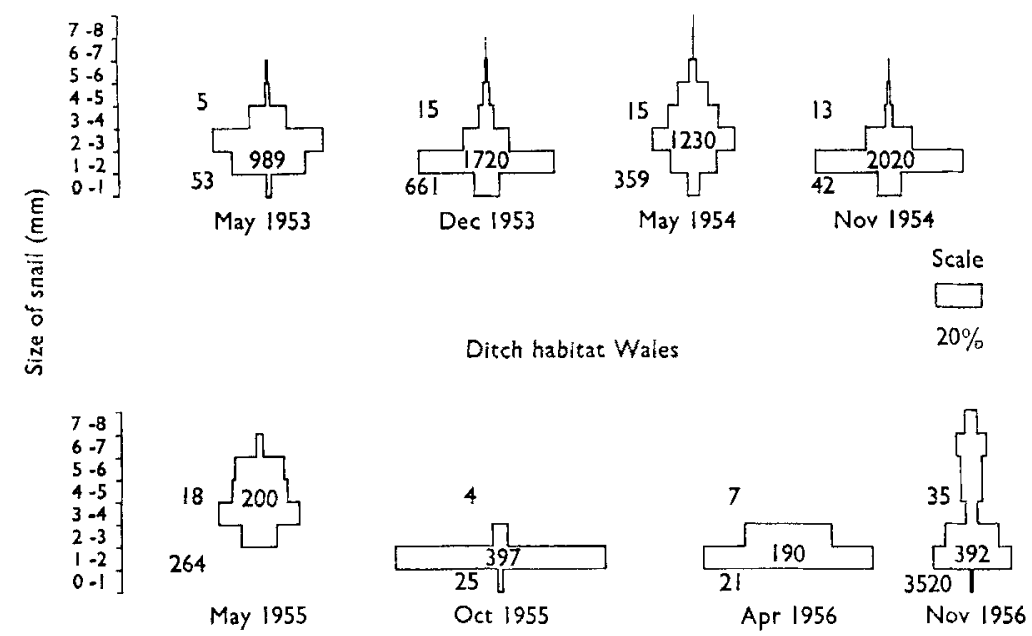

Fig. I. Changes in the size structure of two field populations of Limnaea truncatula, the number of snails in each size group being shown as a percentage of the total population. The figures inside the histograms are the density of snails per $\mathrm{m}^{2}$; the upper numerals outside the histograms are the mean number of rediae per infected snail and the lower numerals are the mean number calculated to be present within snails in each $\mathrm{m}^{2}$ of the habitat.

Consideration of the studies on the Welsh lowland farm habitat (Fig. I) shows that the density of snails was relatively low as compared with the Scottish flush habitat. The form of the size-distribution histograms in 1955 was not repeated in I956, a consequence of different weather in the two years. Snails obtained from the ditch habitat in May 1955 and in November 1956 were larger than their counterparts from the flush habitat but those obtained in October r 955 and April 1956 were much smaller.

As regards the rate of infection in the snails, it will be seen that the November 1956 collection produced about twice the number of rediae per infected snail as did the next most productive collection (in May i955). In terms of numbers of rediae per $\mathrm{m}^{2}$, the figure was almost six times as great as the next highest - for the Scottish flush habitat of December 1953. By contrast, the October 1955 collection showed the smallest number of rediae per snail and the smallest number per $\mathrm{m}^{2}$, although the density of snails was the same as in November $195^{6}$.

The probability that the two habitats were not subjected to the same intensity of infection with fluke eggs does not invalidate the conclusion that there is no simple relationship between the numbers of snails and the size of the parasite population. The results do, however, suggest that the size of the snails may be of importance in influencing the numbers of parasites present. In the flush habitat (Fig. 1) where most of the snails remained small, the population of parasites also was low. In the ditch habitat when on two occasions large snails were found, the intensity of infection was greater. 
Large snails may be older snails or better-fed snails, or both. L. truncatula is usually an annual, breeding commencing in spring and continuing throughout summer. During this period the parent generation dies and normally disappears by autumn. The daughter generation over-winters and forms the parent generation of the following year. In the histograms shown in Fig. I all the collections made in spring consist of parent snails about to breed; those made in autumn and winter consist mainly of daughter snails together with a few parents (the latter are prominent in the ditch habitat in November 1956). From the histograms it can be seen that parent (older) snails are not necessarily larger snails. In fact the size of a snail can be used more exactly as an indication of the suitability of the environment in which it has lived than as andication of its age.

The occurrence of favourable moisture conditions throughout the summer of 1958 in Anglesey provided a further opportunity to study the relationship between the size of the snail and the size of the parasite population. Hand collections were made in a variety of habitats, and over 6000 snails, of which just over rooo proved to be infected, were measured and dissected, the number of rediae present in each snail and the stage of development of the parasite being noted. Rediae containing recognizable cercariae indicated a mature infection; those containing undifferentiated germ balls were classed as immature (Fig. 2). The mean number of rediae in both mature and immature infections found in each size group of snails is shown in Fig. 3 , which indicates an increase in the number of rediae established with the increasing size of the host. It seemed also that the rediae developing in small snails were smaller than those developing in large snails and were unlikely to produce as many cercariae. These conclusions can be substantiated by reference to work carried out under laboratory conditions. It can be shown, in fact, that there is a direct relationship between the state of nutrition of the snail host and the rate of development of the parasite.

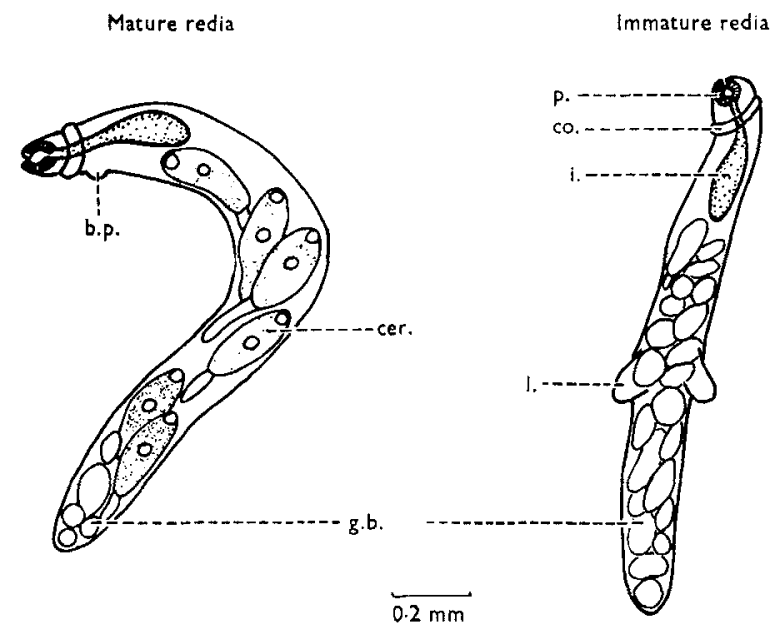

Fig. 2. Difference between a mature and an immature redia of Fasciola hepatica. b.p., birth pore; cer., cercaria; co., collar; g.b., germ ball; i, intestine; 1., lappet; p., pharynx. 


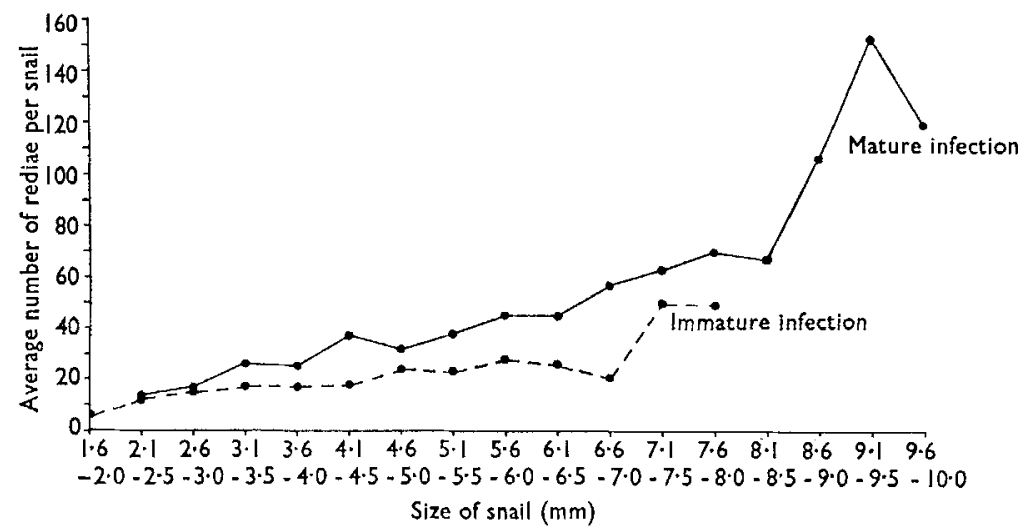

Fig. 3. Relationship between the development of the parasite, Fasciola hepatica, and the size of the snail (Limnaea truncatula) host.

\section{Laboratory studies}

Under suitable conditions in the laboratory $L$. truncatula grows rapidly; snails can reach sexual maturity in 3 or 4 weeks and complete the majority of their growth in 2-3 months. If they are kept in dishes which contain only sterilized sand and filtered pond water, growth, as would be expected, is severely affected, but with snails which have already attained maturity there is little apparent effect and mortality is not appreciably increased, at least over a period of a few weeks.

The effects of starvation on the development of Fasciola hepatica. In a series of experiments under laboratory conditions it was shown (Kendall, I949) that the rate of development of the parasite, as indicated by the number of cercariae which attained full maturity in a given time, was influenced partly by the number of rediae which were present in each snail but more markedly by the amount of food which the snail received. Table I shows that those snails that had had access to unlimited supplies of food contained many more mature cercariae than those kept under

Table I. Effect on the development of the parasite of variation in the nutrition of the snail after multiple infection with Fasciola hepatica

\begin{tabular}{ccc}
\multicolumn{3}{c}{ Well-fed snails } \\
Snail no. & $\begin{array}{c}\text { No. of } \\
\text { rediae }\end{array}$ & $\begin{array}{c}\text { No. of } \\
\text { cercariae }\end{array}$ \\
I & I51 & I353 \\
2 & 296 & I 308 \\
3 & 141 & 1078 \\
4 & 133 & 1299 \\
5 & 152 & 952 \\
6 & 166 & 1390 \\
7 & 136 & 1160 \\
8 & 136 & 1593 \\
9 & 344 & 2275 \\
10 & 200 & 2018 \\
Mean & 185.5 & 1442.6 \\
SE & 23.5 & $131 \cdot 2$
\end{tabular}

$\begin{array}{ccc}\text { Snail no. } & \begin{array}{c}\text { No. of } \\ \text { rediae }\end{array} & \begin{array}{c}\text { No. of } \\ \text { cercariae }\end{array} \\ \text { I I } & 133 & 200 \\ \text { I2 } & 2 \times 5 & 218 \\ \text { I3 } & 169 & 374 \\ \text { I4 } & 2 \times 5 & 134 \\ \text { I5 } & 119 & 391 \\ \text { I6 } & 159 & 14 \\ \text { I7 } & 196 & 9 \\ \text { I8 } & 30 & 131 \\ \text { I9 } & 57 & 292 \\ \text { 20 } & 82 & 480 \\ \text { Mean } & 137.5 & 224.3 \\ \text { SE } & 20.65 & 50.36\end{array}$


starvation conditions. After multiple infection with the miracidia of $F$. hepatica the well-fed snails, with a mean number of 185.5 rediae per snail, had a mean number of mature cercariae of I $442 \cdot 6$ (SE I 3 I 2 ) but for the starved snails the mean was only $224^{\circ} 3$. The effect of feeding the snails was to accelerate the rate at which the parasite matured so that at a given time many more mature cercariae had been formed.

Variations in the numbers of rediae in each snail. The number of rediae which develop in each snail, as distinct from the rate at which they mature, is apparently influenced to some extent by the amount of available food, but can be varied more directly by subjecting the snail to infection either with a single miracidium (normally leading to the formation of not more than forty rediae) or to multiple infection (when considerably larger numbers of rediae are likely to develop (Tables I and 2)).

Table 2. Relationship between the number of rediae and their state of maturity in the snail after infection with Fasciola hepatica

$\begin{array}{cccc}\text { Snail no. } & \begin{array}{c}\text { No. of } \\ \text { rediae }\end{array} & \begin{array}{c}\text { No. of } \\ \text { cercariae }\end{array} & \begin{array}{c}\text { No. of } \\ \text { cercariae/redia }\end{array} \\ 1 & \text { I4 } & \text { I65 } & \text { I I.8 } \\ 2 & 21 & 253 & 12 \cdot 0 \\ 3 & 23 & 160 & 7 \cdot 0 \\ 4 & 28 & 228 & 8 \cdot 1 \\ 5 & 73 & \text { I } 16 & \text { 1.6 } \\ 6 & 98 & 200 & 2 \cdot 0 \\ 7 & \text { I54 } & 149 & 1 \cdot 0\end{array}$

Table 2 shows that an increase in the number of rediae is associated with a decrease in the rate of development of the parasite as evidenced by the number of mature cercariae present in each redia.

\section{Discussion}

The field and laboratory observations described suggest a well-adjusted relationship between $F$. hepatica and its snail host; more parasites competing for a given quantity of food tend to grow less rapidly; more available food leads to an increase in their rate of growth. That such a happy relationship between host and parasite need not necessarily exist has been shown by Kendall (1950) who in the laboratory infected various species of Limnaea not normally parasitized in nature and showed a very ill-adjusted relationship compared with that in the normal host.

$F$. hepatica has a wide distribution in a number of mammalian hosts so that $L$. truncatula is generally very subject to infection. Consideration of the ecology of the snail suggests the virtual necessity for close integration in development between host and parasite. L. truncatula is an animal with an unsettled background, living in the intermediate zone between water and land, and from the nature of its habitat subject to extremes of environmental conditions. To meet these it has evolved the ability at one time to grow and multiply with extreme speed and at another to undergo prolonged periods of aestivation when metabolic processes become dormant and feeding ceases. Under such conditions the parasite also becomes quiescent. Without some such regulating mechanism it is easy to see that infection could lead to destruction of the host and self-immolation of the parasites. 
Such a relationship indeed seems inevitable and it is curious that similar instances of adjustment between the metabolism of host and parasite appear to have been recorded so rarely. Perhaps Daniel's (1932) work on the oriental fruit moth and its braconid parasite is another example of a phenomenon which closer investigation may show to be commoner than at present appears.

\section{REFERENCES}

Daniel, D. M. (1932). Tech. Bull. N.Y. agric. Exp. Sta. no. I87.

Kendall, S. B. (1949). F. Helminth. 23, i79.

Kendall, S. B. (1950). F. Helminth. 24, 63 .

Ollerenshaw, C. B. (1958). Agriculture, Lond., 65, 23 I.

Thomas, A. P. (1883). Quart. F. micr. Sci. NS, 23, 99. 